\title{
Laser Processing of Tungsten Powder with Femtosecond Laser Radiation
}

\author{
Robby EBERT, Frank ULLMANN, Dorena HILDEBRANDT, Joerg SCHILLE, Lars HARTWIG, Sascha KLOETZER, \\ Andre STREEK and Horst EXNER
}

University of Applied Science, Laser Institute, 17 Technikumplatz, 09648 Mittweida, Germany

\begin{abstract}
Laser irradiation of dispensed tungsten powder layers with grain sizes smaller than $1 \mu \mathrm{m}$ was investigated using high-repetition femtosecond laser systems. Laser processing was performed line by line with repetition rates up to $1 \mathrm{MHz}$ and varying parameters such as laser power, processing speed, number of scans and pressure. In addition to the expected material ablation and melting, novel phenomena such as crystallisation, emergence of ripple structures, extensive agglomeration and the formation of nano-wires will be discussed qualitatively with the help of SEM photographs. Dependence on light pressure, pulse overlap and irradiated energy per unit length will be demonstrated. High-resolution microstructures will be discussed as a first application of innovative laser microsintering technology using high-repetition femtosecond laser pulses.
\end{abstract}

DOI:10.2961/jlmn.2012.01.0007

Keywords: femtosecond laser, high-repetition rate laser, laser micro sintering, nano-ripple, tungsten

\section{Introduction}

Ultrashort pulses are commonly used for precise ablation of layers or for 3D microstructuring [1-3]. Glass welding is known also [4]. Further investigations demonstrate the possibility of targeted fabrication of nano- and microstructures on various material surfaces $[5,6]$. However, femtosecond laser irradiation of dispensed loose powder layers with the objective of producing sintered structures has not been investigated thus far. By varying the pulse energy and the scan velocity, it should be possible to find parameters under which radiation pressure and plasma effects bring about compaction of the powder layers, and the applied energy per unit length heats up the powder layer to just below the melting point. Other than the short exposure time, this would largely correspond to the classic sintering process.

\section{Experimental principles}

An existing laser microsintering facility was used for the investigations. It consists of a femtosecond laser (Table 1), an adjustable attenuator for selecting the pulse energy, a pulse divider, a scanner for beam deflection and focussing, and a vacuum sintering chamber.

Table 1 Laser parameters.

\begin{tabular}{|c|c|c|c|}
\hline $\begin{array}{l}\text { Wave } \\
\text { length }\end{array}$ & $\begin{array}{c}\text { Pulse } \\
\text { duration }\left(\operatorname{sech}^{2}\right)\end{array}$ & $\begin{array}{l}\text { Pulse repeti- } \\
\text { tion rate }\end{array}$ & $\begin{array}{l}\text { Focus spot } \\
\text { radius }\end{array}$ \\
\hline$\lambda[\mathrm{nm}]$ & $\mathrm{t}[\mathrm{fs}]$ & $\mathrm{f}[\mathrm{MHz}]$ & $\mathrm{w}_{0.86}[\mu \mathrm{m}]$ \\
\hline 1030 & 180 & 0.125 and 1 & 18 \\
\hline
\end{tabular}

The powder surface was irradiated using linear scans 1 to 50 times. The parameters that were varied were the incident laser power $\mathrm{P}_{\mathrm{av}}(0.4 \ldots 7.5 \mathrm{~W})$ and consequently the pulse energy $\mathrm{Q}_{\mathrm{P}}(0.4 \ldots 7.5 \mu \mathrm{J})$, and the pulse peak power $\mathrm{P}_{\mathrm{P}}(1.96 \ldots 36.67 \mathrm{MW})$ (see Table 2). The radiation pressure
$\mathrm{p}_{\mathrm{I}}$ at reflecting surfaces $(\mathrm{R}=1)$ at the applied intensity goes up to $4787 * 10^{5} \mathrm{~Pa}\left(\mathrm{p}_{\mathrm{I}}=2 * \mathrm{I}_{\max } / \mathrm{c}\right)$. The vacuum pressure $\mathrm{p}$ was $0.05 \mathrm{~Pa}$. Helium was used as residual gas in selected experiments.

Table 2 Laser pulse parameters.

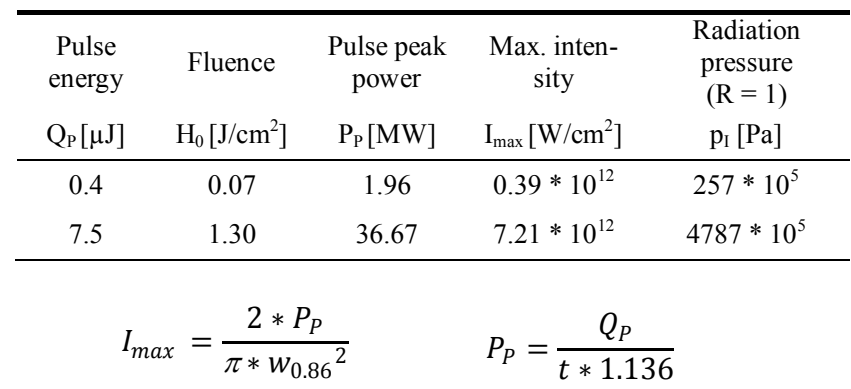

The experiments used tungsten powder supplied by Goodfellow. It is specified by the manufacturer at a grain size lower than $1 \mu \mathrm{m}$ with major part at $300 \mathrm{~nm}$. The measured bulk density $\rho_{P}$ was $2.8 \mathrm{~g} / \mathrm{cm}^{3}$, which corresponds to a relative powder density of approximately $15 \%$. The powder surface was normally produced by means of one dispensing process by special cylindrical dispenser [7]. The thickness of the powder layer was approximately $1000 \mu \mathrm{m}$.

In order to prepare a defined powder surface, it was cleaned before every experiment through laser irradiation. To this end, the powder surface was irradiated line by line with a pulse energy of $0.7 \mu \mathrm{J}$ and a scan velocity of $4.5 \mathrm{~m} / \mathrm{s}$ With these parameters, plasma was observed during the first scan but not during subsequent scans. No visual effect was observed on the powder surface. Based on scanning electron microscope (SEM) imaging, however, it became clear that the powder surface had already been slightly affected by the irradiation. The irradiated regions appeared lighter in the SEM images.

Scan velocity $\mathrm{v}$ and pulse repetition rate $\mathrm{f}$ were varied in order to investigate the effect of lateral pulse-to-pulse 
travel distance a, and of energy per unit length $\mathrm{Q}_{\mathrm{S}}$, on the sintering process (Table 3 ). The applied energy per unit length is the ratio of the average laser power and scan velocity. The scan offset distance 1 was $50 \mu \mathrm{m}$ in all basic experiments.

Table 3 Process parameters.

\begin{tabular}{ccccc}
\hline $\begin{array}{c}\text { Laser } \\
\text { power } \\
\mathrm{P}_{\mathrm{av}}[\mathrm{W}]\end{array}$ & $\begin{array}{c}\text { Pulse repeti- } \\
\text { tion rate } \\
\mathrm{f}[\mathrm{MHz}]\end{array}$ & $\begin{array}{c}\text { Scan } \\
\text { velocity } \\
\mathrm{v}[\mathrm{m} / \mathrm{s}]\end{array}$ & $\begin{array}{c}\text { Pulse } \\
\text { distance } \\
\mathrm{a}[\mu \mathrm{m}]\end{array}$ & $\begin{array}{c}\text { Energy per } \\
\text { unit length } \\
\mathrm{Q}_{\mathrm{S}}[\mathrm{J} / \mathrm{m}]\end{array}$ \\
\hline 0.4 & 1 & 0.1 & 0.1 & 4 \\
0.4 & 1 & 5 & 5 & 0.08 \\
7.5 & 1 & 0.1 & 0.1 & 75 \\
7.5 & 1 & 5 & 5 & 1.5 \\
0.875 & 0.125 & 0.3125 & 2.5 & 2.8 \\
0.875 & 0.125 & 5 & 40 & 0.175 \\
\hline
\end{tabular}

The formation of plasmons from the free electron gas is significant, particularly in case of the irradiation of solid body surfaces with femtosecond lasers. The plasmons are resonant oscillation modes of the electron gas. One distinguishes between volume and surface plasmons. In the case of metallic nanoparticles whose dimensions are much smaller than the wavelength of light, the plasmons lead to unusual optical properties. Depending on the resonant frequency, there occurs narrow-band absorption of light and light scattering into the far field. In addition, there is an amplified near field (factor $10-10^{6}$ ) around the particle, with the typical spatial extent being several $10 \mathrm{~nm}$ [8]. The amplified near field can lead to nanoablation even at low laser beam intensities [9].

Due to the short pulse duration, coupling of the laser beam energy occurs first in the free electron gas, and after an interval of a few picoseconds the energy is transferred to the solid lattice (two-temperature model). The excitation of the plasmons and the coupling factor to the phonons are responsible for the qualitative formation of nanoripples [10]. The formation of nanoripples has also been observed when irradiating tungsten surfaces [11].

When using the classical heat conduction equation, the irradiated powder grains would take on different temperatures depending on their size [7]. The temperature equalisation in the powder bed is likely to take place largely by through radiation processes, i.e. considerably faster than through heat conduction.

The irradiation of a loose powder layer with femtosecond laser pulses is, therefore, a very complex process. Hence, the encountered effects will first be recorded, and then considered in depth in later investigations.

\section{Results and discussion}

\subsection{Intensity lower than $1.6 * 10^{12} \mathrm{~W} / \mathrm{cm}^{2}$, Energy per unit length lower than $0.7 \mathrm{~J} / \mathrm{m}, \mathrm{f}=1 \mathrm{MHz}$}

When using both low laser intensity and low energy per unit length under multiple irradiations, the powder grains exhibited nanoripple formation (Fig. 1). Due to the low applied energy per unit length and since the powder grains have largely retained their crystal structure, it can be assumed that direct nanostructuring of the tungsten particles without separate melt formation has taken place.

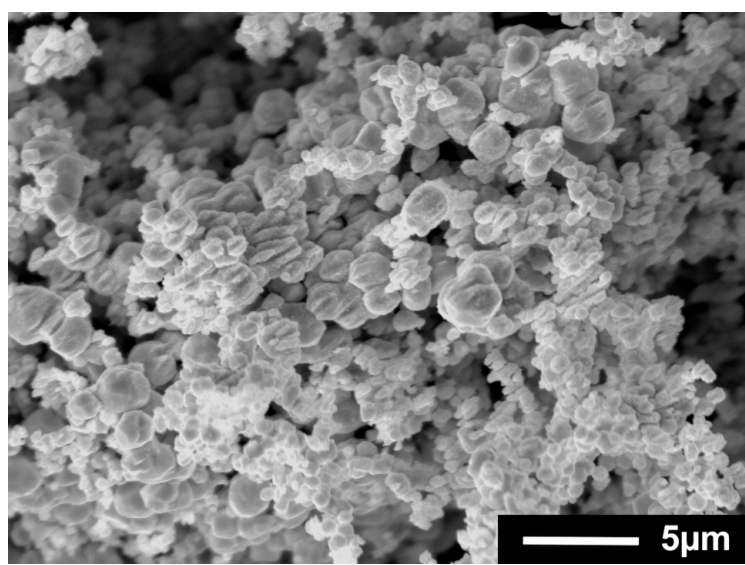

Fig. 1 SEM image, $I_{\max }=1.55 * 10^{12} \mathrm{~W} / \mathrm{cm}^{2}, \mathrm{Q}_{\mathrm{S}}=0.4 \mathrm{~J} / \mathrm{m}$, $\mathrm{v}=4 \mathrm{~m} / \mathrm{s}, \mathrm{a}=4 \mu \mathrm{m}, 20$ scans.

The formation of fibrous nanoparticle aggregates [12] was observed when conducting the experiments under a helium pressure $\mathrm{p}=0.5 * 10^{5} \mathrm{~Pa}$ (Fig. 2).

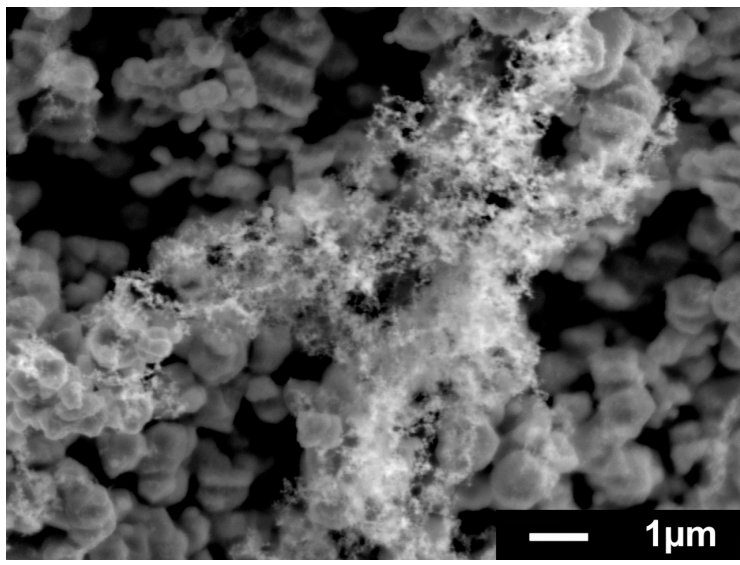

Fig. 2 SEM image, $I_{\max }=1.55 * 10^{12} \mathrm{~W} / \mathrm{cm}^{2}, \mathrm{Q}_{\mathrm{S}}=0.32 \mathrm{~J} / \mathrm{m}$, $\mathrm{v}=5 \mathrm{~m} / \mathrm{s}, \mathrm{a}=5 \mu \mathrm{m}, 5$ scans.

\subsection{Intensity lower than $1.6 * 10^{12} \mathrm{~W} / \mathrm{cm}^{2}$, Energy per unit length in a range of $0.7 \ldots 20 \mathrm{~J} / \mathrm{m}, \mathrm{f}=1 \mathrm{MHz}$}

Under multiple irradiation, and starting from 5 scans at the lowest intensity $\mathrm{I}_{\max }=0.39 * 10^{12} \mathrm{~W} / \mathrm{cm}^{2}$ with a small pulse-to-pulse travel distance $\mathrm{a}=0.1 \ldots 0.3 \mu \mathrm{m}$, the irradiated region exhibited the formation of large-area slabs. The thickness of the slabs was approximately $10 \mu \mathrm{m}$. They exhibited a curvature which increased with the number of irradiations. It appeared as though the powder layer had undergone large-area sintering and was under strong internal mechanical stress (Fig. 3). Thus far there is no clue as yet for an explanation of this effect. It is noteworthy that at a line spacing of $50 \mu \mathrm{m}$ there was no overlapping of the focus spot diameter. At higher intensities, $\mathrm{I}_{\max }=3.52 * 10^{12} \mathrm{~W} / \mathrm{cm}^{2}$, the effect was also observed with wider pulse-to-pulse travel distances $(\mathrm{a}>1 \mu \mathrm{m})$. 


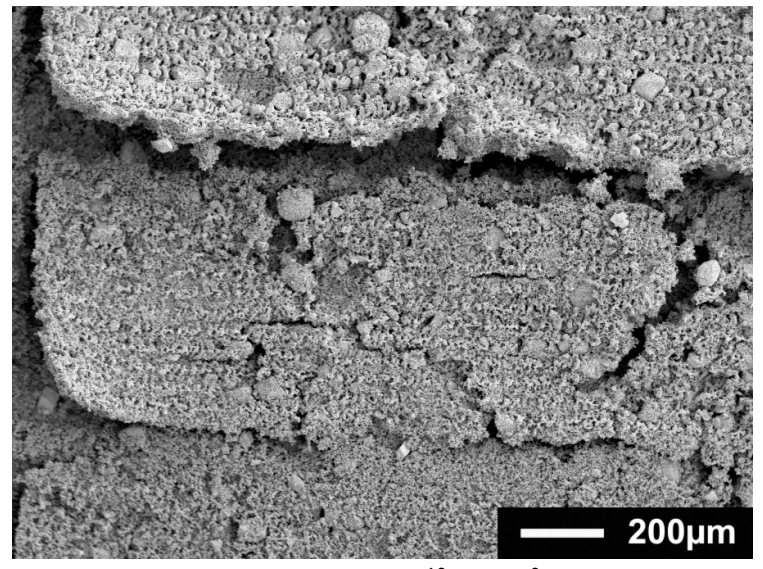

Fig. 3 SEM image, $I_{\max }=0.69 * 10^{12} \mathrm{~W} / \mathrm{cm}^{2}, Q_{\mathrm{S}}=2.4 \mathrm{~J} / \mathrm{m}$, $\mathrm{v}=0.3 \mathrm{~m} / \mathrm{s}, \mathrm{a}=0.3 \mu \mathrm{m}, 20$ scans.

3.3 Intensity in a range of $1.6 \ldots .5 * 10^{12} \mathrm{~W} / \mathrm{cm}^{2}$, Energy per unit length in a range of $0.7 \ldots 20 \mathrm{~J} / \mathrm{m}$, $\mathbf{f}=\mathbf{1} \mathbf{M H z}$

When increasing the intensity and the energy per unit length, the tracks exhibited an increased formation of melts (Fig. 4). Due to the surface tension, the predominant effect was of spherical melt formations. Depending on the applied intensity and scan velocity, there was either formation of crystals (Fig. 5) or melt pearls with nanoripple structures (Fig. 6). The crystals formed preferentially at a pulse-topulse travel distance of 0.3 to $0.8 \mu \mathrm{m}$, and an increased intensity of $\mathrm{I}_{\max }=4.05 * 10^{12} \mathrm{~W} / \mathrm{cm}^{2}$.

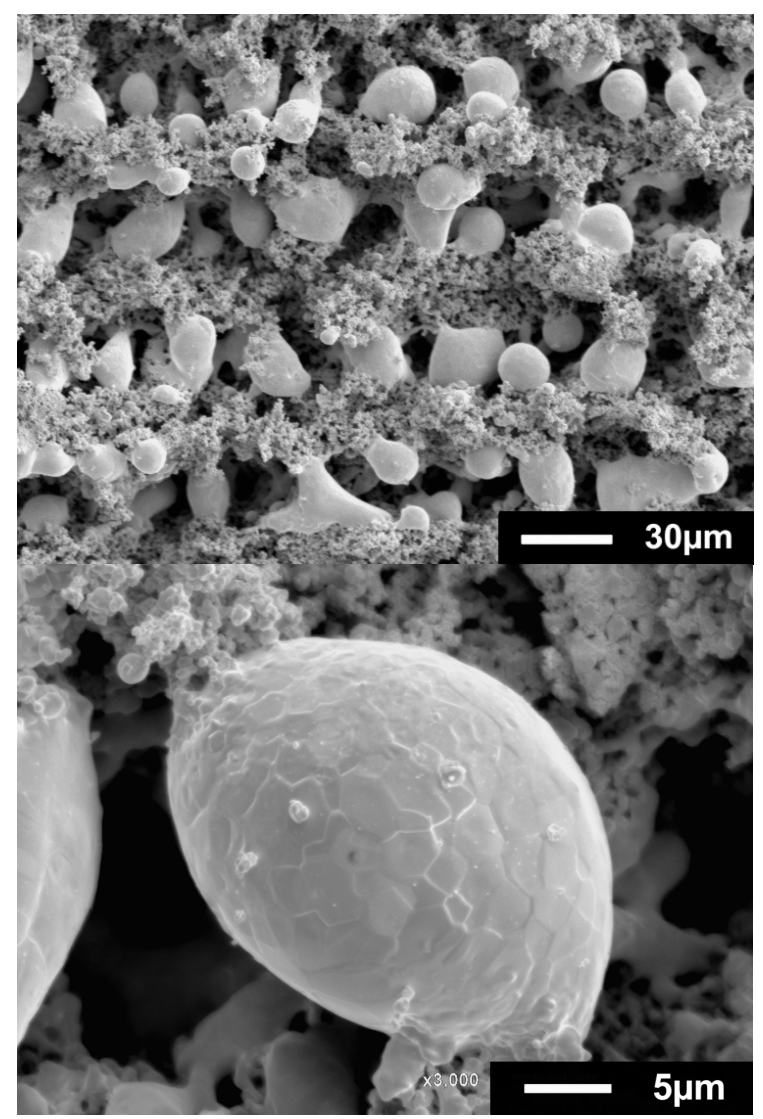

Fig. 4 \& 5 SEM images, $I_{\max }=4.05 * 10^{12} \mathrm{~W} / \mathrm{cm}^{2}, \mathrm{Q}_{\mathrm{S}}=14 \mathrm{~J} / \mathrm{m}$, $\mathrm{v}=0.3 \mathrm{~m} / \mathrm{s}, \mathrm{a}=0.3 \mu \mathrm{m}, 1 \mathrm{scan}$.
Evidently, with these parameters there is sufficient time for the formation of crystalline structures. The crystalline structure was absent when the scan velocity was decreased to $0.1 \mathrm{~m} / \mathrm{s}$ and the intensity to $I_{\max }=1.76 * 10^{12} \mathrm{~W} / \mathrm{cm}^{2}$. Instead, nanoripples occurred on the amorphous melt pearls. The generally observed conditions for the formation were a relatively high pulse overlap or a multiple scan. It is noteworthy that ripple formation occurred in two different directions. Firstly, the deep laser-induced ripples are present. In addition, superficial ripples transverse to those can be seen (Fig. 6).

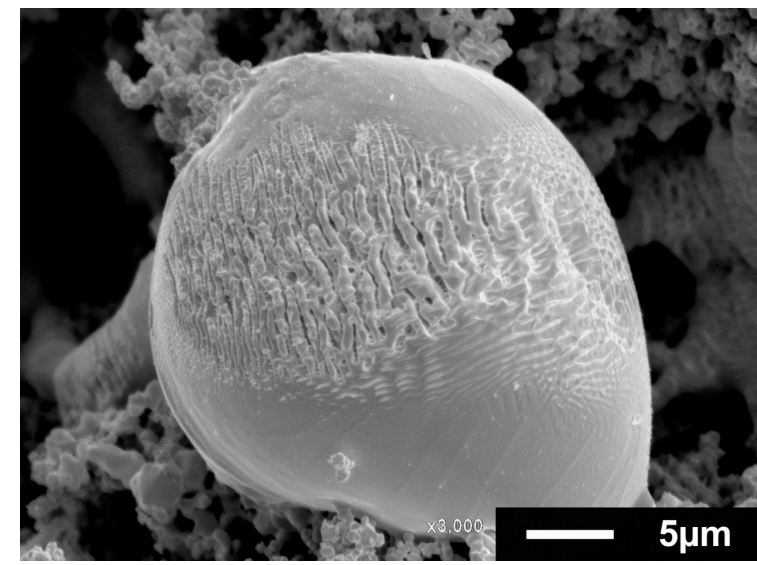

Fig. 6 SEM image, $I_{\max }=1.76 * 10^{12} \mathrm{~W} / \mathrm{cm}^{2}, \mathrm{Q}_{\mathrm{S}}=18 \mathrm{~J} / \mathrm{m}$, $\mathrm{v}=0.1 \mathrm{~m} / \mathrm{s}, \mathrm{a}=0.1 \mu \mathrm{m}, 1 \mathrm{scan}$.

Significant reduction of energy per unit length by increasing the scan velocity led to a delicate melt track with a width of approximately $15 \mu \mathrm{m}$ (Fig. 7). Under multiple scans, however, the melt strands were transected and the formation of individual melt pearls took place.

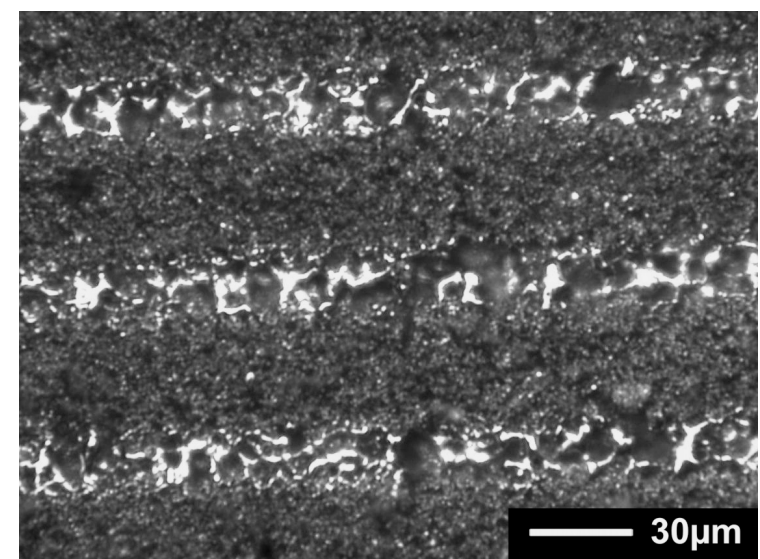

Fig. 7 Digital image, $\mathrm{I}_{\max }=2.13 * 10^{12} \mathrm{~W} / \mathrm{cm}^{2}, \mathrm{Q}_{\mathrm{S}}=2.2 \mathrm{~J} / \mathrm{m}$, $\mathrm{v}=1 \mathrm{~m} / \mathrm{s}, \mathrm{a}=1 \mu \mathrm{m}, 1 \mathrm{scan}$.

Increasing the intensity whilst simultaneously reducing the energy per unit length even further, led to a decrease in melt volume (Fig. 8). Only individual molten microregions were now present, with maximum dimensions of $5 * 10 \mu \mathrm{m}^{2}$. Cohesion was no longer exhibited. 


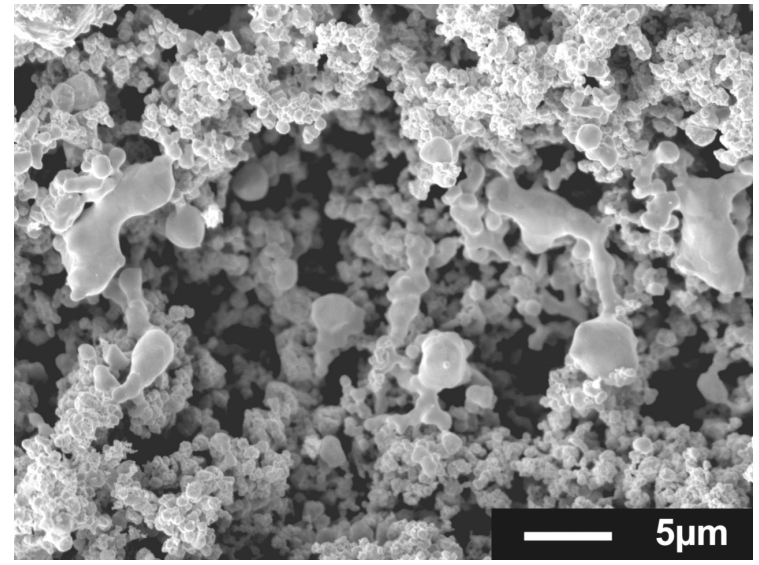

Fig. 8 SEM image, $I_{\max }=3.85 * 10^{12} \mathrm{~W} / \mathrm{cm}^{2}, \mathrm{Q}_{\mathrm{S}}=0.8 \mathrm{~J} / \mathrm{m}$, $\mathrm{v}=5 \mathrm{~m} / \mathrm{s}, \mathrm{a}=5 \mu \mathrm{m}, 1 \mathrm{scan}$.

Under multiple scans, cross-linking increased again (Fig. 9). At the same time, deep nanoripples formed in the melt structures.

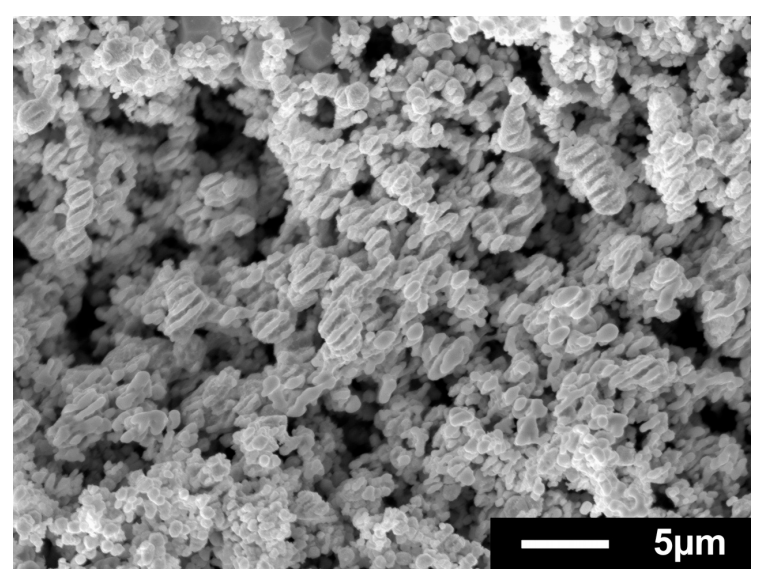

Fig. 9 SEM image, $\mathrm{I}_{\max }=3.85 * 10^{12} \mathrm{~W} / \mathrm{cm}^{2}, \mathrm{Q}_{\mathrm{S}}=0.8 \mathrm{~J} / \mathrm{m}$, $\mathrm{v}=5 \mathrm{~m} / \mathrm{s}, \mathrm{a}=5 \mu \mathrm{m}, 10$ scans.

\subsection{Intensity higher than $5 * 10^{12} \mathrm{~W} / \mathrm{cm}^{2}$, Energy per unit length in a range of $0.7 \ldots 3 \mathrm{~J} / \mathrm{m}, \mathrm{f}=125 \mathrm{kHz}$}

Since the scan velocity was limited to $\mathrm{v}=5 \mathrm{~m} / \mathrm{s}$, the effect of an increased pulse-to-pulse travel distance could only be investigated by reducing the laser pulse repetition rate to $125 \mathrm{kHz}$. This made possible the application of high intensity together with moderate to low energy per unit length. At a pulse-to-pulse travel distance of $\mathrm{a}=2.5 \mu \mathrm{m}$, the formation of highly fissured structures at the centre of the track was observed, and also melt and ripple formation at the edge (Fig. 10). This showed that on the one hand, the intensity was sufficiently high to cause compaction of the powder, but on the other, the applied energy - especially in the region of lower intensity at the edge - was still so high that disruptive secondary effects took place.

Increasing the pulse-to-pulse travel distance between 5 to $20 \mu \mathrm{m}$ led to the disappearance of the melts (Fig. 11). The powder grains were firmly joined to each other. The structure is limited to a width of approximately $15 \mu \mathrm{m}$. When the mean energy per unit length is reduced by increasing the pulse-to-pulse travel distance, this decreases the "superfluous" melt formation to such an extent that the resulting structures are similar to classic sintered for- mations. From a pulse-to-pulse travel distance wider than $20 \mu \mathrm{m}$ onward, the compactness of the structures was markedly reduced. Decreasing the intensity to $\mathrm{I}_{\max }=5.81 * 10^{12} \mathrm{~W} / \mathrm{cm}^{2}$ led, starting at a pulse-to-pulse travel distance wider than $10 \mu \mathrm{m}$, to a decline in the sintered structures.

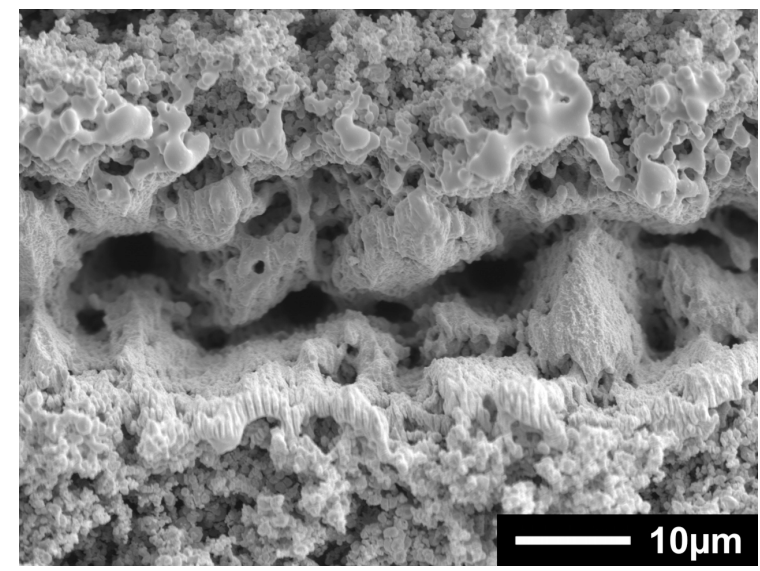

Fig. 10 SEM image, $I_{\max }=6.74 * 10^{12} \mathrm{~W} / \mathrm{cm}^{2}, \mathrm{Q}_{\mathrm{S}}=2.8 \mathrm{~J} / \mathrm{m}$, $\mathrm{v}=0.3125 \mathrm{~m} / \mathrm{s}, \mathrm{a}=2.5 \mu \mathrm{m}, 10$ scans.

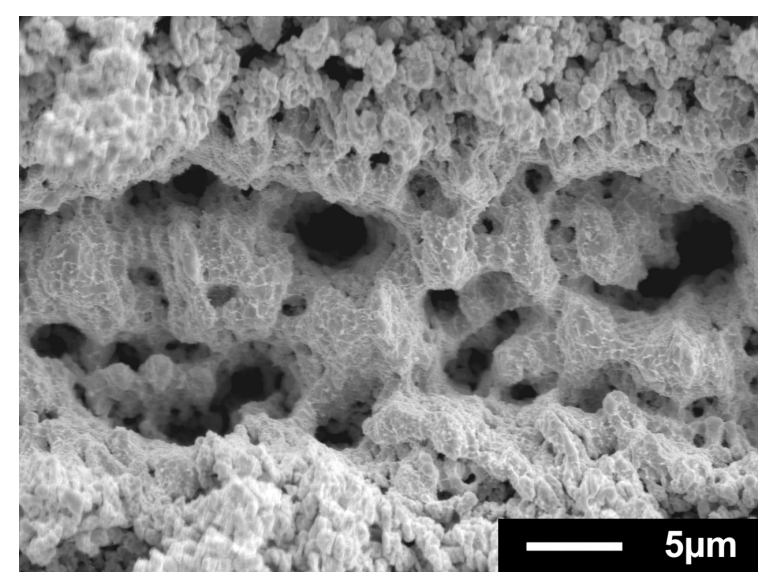

Fig. 11 SEM image, $I_{\max }=6.74 * 10^{12} \mathrm{~W} / \mathrm{cm}^{2}, Q_{\mathrm{S}}=0.7 \mathrm{~J} / \mathrm{m}$, $\mathrm{v}=1.25 \mathrm{~m} / \mathrm{s}, \mathrm{a}=10 \mu \mathrm{m}, 10$ scans.

The high radiation pressure, $\mathrm{p}_{\mathrm{I}}=4787 * 10^{5} \mathrm{~Pa}$, led to high forces acting on the particles, either $177 \mu \mathrm{N}$ (diameter $=1 \mu \mathrm{m})$ or $17 \mu \mathrm{N}$ (diameter $=0.3 \mu \mathrm{m})$. These forces were 9 orders of magnitude higher than the acting gravitational forces. Due to the ultra short exposure time, however, these high forces did not lead to significant displacement of the particles (only approximately $10^{-16} \mathrm{~m}$ ) or to significant kinetic energies (only approximately $10^{-14} \mu \mathrm{J}$ ). The radiation pressure, therefore, has no detectable effect on the sintering process.

The formation of the sintered structures at high intensities should, rather, be attributed to the same mechanisms as in laser microsintering with ns pulses. The vaporisation of material at the powder surface leads to a recoil, which accelerates the particles towards the powder bed. The expansion of the material vapour plasma also exerts a pressure on the forming surface of the sintered structure. When using ns pulses, this structure is characterised by melts. When sintering with fs laser pulses, it seems initially as though no melt is present. Future investigations will explore this ef- 
fect in more detail, and a model for the formation of the sintered structures will be constructed.

Nanospikes appear to have formed at the surface of the sintered structure (Fig. 12), however not in association with nanoripples as reported by other research groups [13]. The nanospikes will be investigated in greater detail by means of high-resolution SEM imaging.

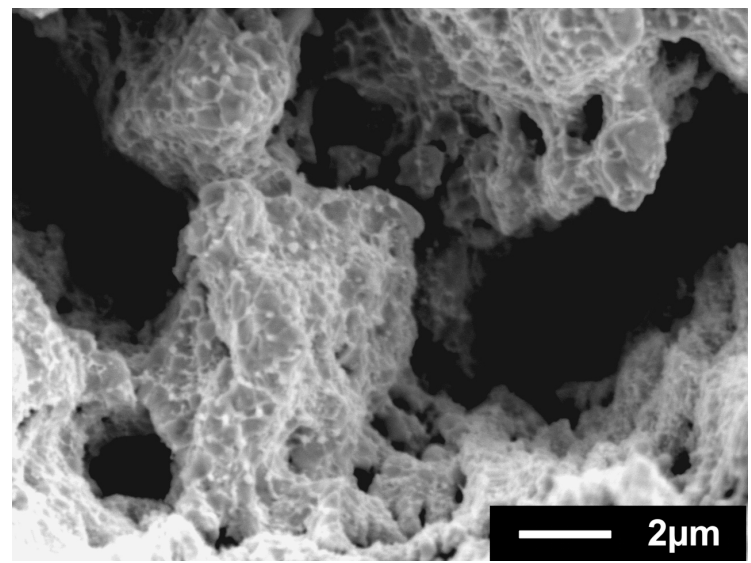

Fig. 12 SEM image, $I_{\max }=6.74 * 10^{12} \mathrm{~W} / \mathrm{cm}^{2}, \mathrm{Q}_{\mathrm{S}}=0.7 \mathrm{~J} / \mathrm{m}$, $\mathrm{v}=1.25 \mathrm{~m} / \mathrm{s}, \mathrm{a}=10 \mu \mathrm{m}, 10$ scans.

\subsection{Intensity higher than $5 * 10^{12} \mathrm{~W} / \mathrm{cm}^{2}$, Energy per unit length higher than $40 \mathrm{~J} / \mathrm{m}, \mathrm{f}=1 \mathrm{MHz}$}

When maintaining the high intensity and increasing energy per unit length considerably by reducing scan velocity, significant melt formation could be observed. However, since at the same time the high intensity led to greater plasma formation, the melt was pushed into deeper regions of the powder. There was formation of relatively wellbounded molten trench structures, with widths of about $30 \mu \mathrm{m}$ and vertical form walls (Fig. 13) with a depth of up to $138 \mu \mathrm{m}$.

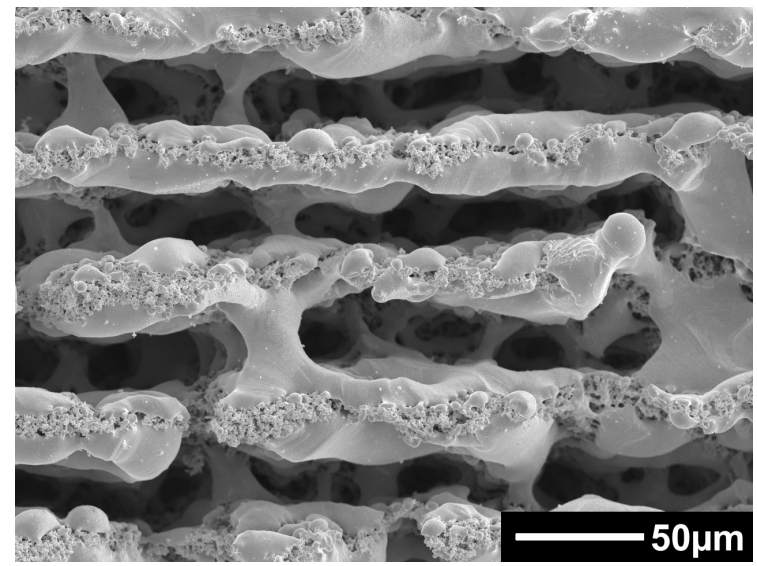

Fig. 13 Optical image, $I_{\max }=6.53 * 10^{12} \mathrm{~W} / \mathrm{cm}^{2}, \mathrm{Q}_{\mathrm{s}}=68 \mathrm{~J} / \mathrm{m}$, $\mathrm{v}=0.1 \mathrm{~m} / \mathrm{s}, \mathrm{a}=0.1 \mu \mathrm{m}, 1$ scan.

\subsection{Effects of pressure / gas}

The structures of the experimental series created under a helium pressure of $\mathrm{p}=0.5 * 10^{5} \mathrm{~Pa}$, possessed lower resolution than those created in vacuum. In addition, higher laser power was needed in order to achieve structure sizes similar to those achieved in vacuum. The likely reason is the generated residual gas plasma, which is additional to the always present material vapour plasma. Under these conditions, it reduces the process efficiency and the attainable resolution.

\subsection{Sintering areas}

By decreasing the line spacing to $1=10 \mu \mathrm{m}$, it proved possible to sinter continuous surfaces (Fig. 14 and 15). Sintered structures of varying sizes in the range between 1 to $10 \mu \mathrm{m}$ were formed, depending on the scan velocity used.

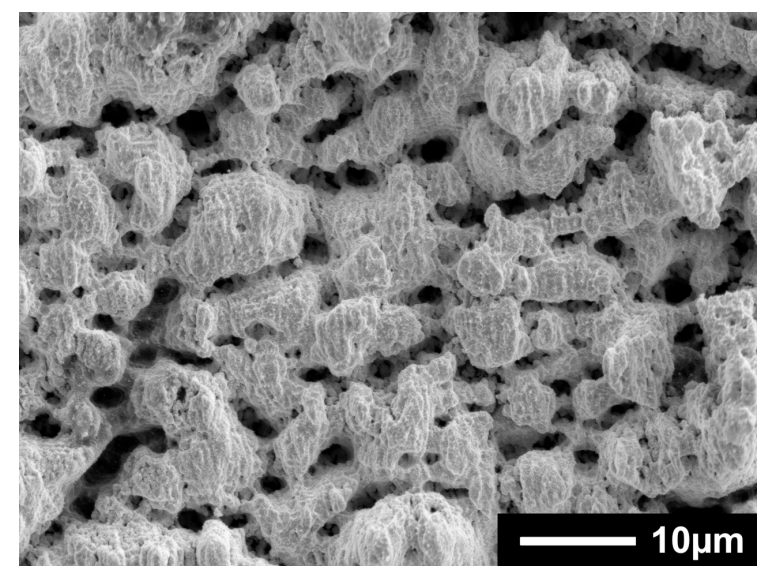

Fig. 14 SEM image, $I_{\max }=6.74 * 10^{12} \mathrm{~W} / \mathrm{cm}^{2}, Q_{\mathrm{S}}=0.7 \mathrm{~J} / \mathrm{m}$, $\mathrm{v}=1.25 \mathrm{~m} / \mathrm{s}, \mathrm{a}=10 \mu \mathrm{m}, \mathrm{l}=10 \mu \mathrm{m}, \mathrm{f}=125 \mathrm{kHz}, 10$ scans.

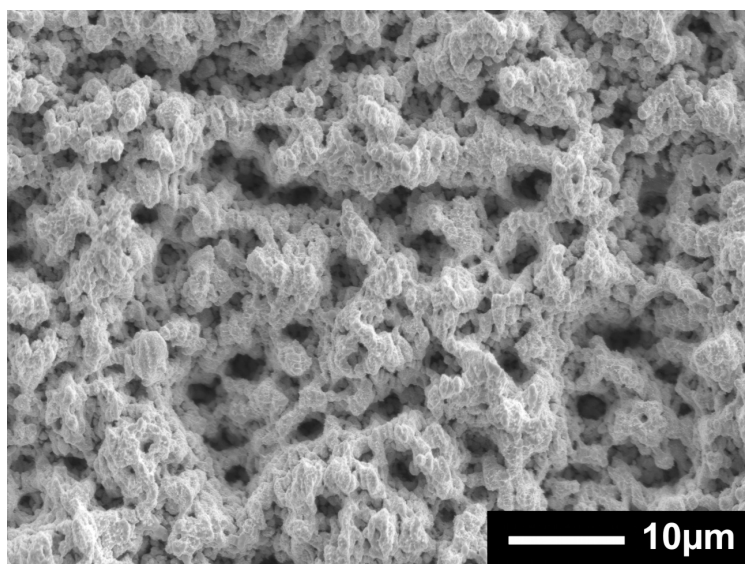

Fig. 15 SEM image, $\mathrm{I}_{\max }=6.74 * 10^{12} \mathrm{~W} / \mathrm{cm}^{2}, \mathrm{Q}_{\mathrm{S}}=0.23 \mathrm{~J} / \mathrm{m}$, $\mathrm{v}=3.75 \mathrm{~m} / \mathrm{s}, \mathrm{a}=30 \mu \mathrm{m}, \mathrm{l}=10 \mu \mathrm{m}, \mathrm{f}=125 \mathrm{kHz}, 10$ scans.

\subsection{Highly resolved structures}

The first experiments designed to create defined gridlike structures demonstrate the fundamental suitability of the method and its ability to achieve high resolution (Fig. 16 \& 17). The height of the applied structure was ca. $1 \mu \mathrm{m}$. The carrier platform was not lowered during the 6 dispensing procedures. The grid spacing used was $50 \mu \mathrm{m}$, the produced optical line width (Fig. 16) is approximately $17 \mu \mathrm{m}$. However, the structures identified in the SEM image seem considerably wider (Fig. 17). 


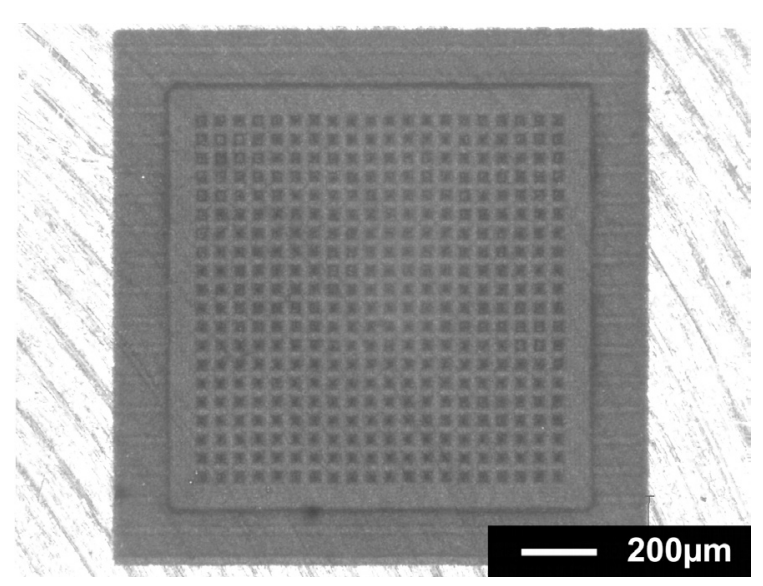

Fig. 16 Optical image, grid-like structure, $\mathrm{I}_{\max }=1.77 * 10^{12} \mathrm{~W} / \mathrm{cm}^{2}, \mathrm{Q}_{\mathrm{S}}=3 \mathrm{~J} / \mathrm{m}, \mathrm{v}=0.6 \mathrm{~m} / \mathrm{s}$, $\mathrm{f}=1 \mathrm{MHz}, 6$ scans and dispensing procedures.

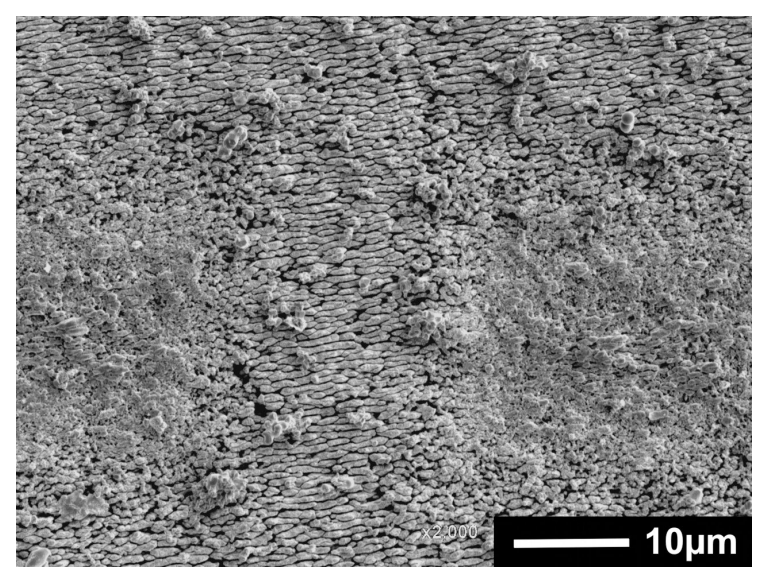

Fig. 17 SEM image, grid-like structure, $\mathrm{I}_{\max }=1.77 * 10^{12} \mathrm{~W} / \mathrm{cm}^{2}$, $\mathrm{Q}_{\mathrm{S}}=3 \mathrm{~J} / \mathrm{m}, \mathrm{v}=0.6 \mathrm{~m} / \mathrm{s}, \mathrm{f}=1 \mathrm{MHz}, 6$ scans and dispensing procedures.

\section{Summary and outlook}

The fundamental feasibility of laser microsintering with a high-repetition femtosecond laser was demonstrated. Lateral pulse-to-pulse travel distances between 5 to $20 \mu \mathrm{m}$ have proved to be advantageous at an applied intensity of $\mathrm{I}_{\max }=6.74 * 10^{12} \mathrm{~W} / \mathrm{cm}^{2}$ and a pulse repetition rate of $\mathrm{f}=$ $125 \mathrm{kHz}$. Sintered structures were created for the first time that resembles the classic sintered formations. The effect of the temporal pulse-to-pulse travel distance on the sintering outcome will be investigated in greater detail in the future by varying the pulse repetition rate.

The sintering of highly resolved structures is just as possible as is that of thin layers. The fabrication of micro/nano-sieves using this method will be investigated in the future. Investigating the applicability of the method to other materials will also be focused upon.

\section{Acknowledgments}

The authors wish to thank BMBF for supporting the Innoprofile project "Rapid Microtooling Using Laser-based Methods“(FKZ: 03IP506).

\section{References}

[1] C. Momma, S. Nolte, B. N. Chichkov, F. v. Alvensleben, A. Tuennermann: Precise laser ablation with ultrashort pulses, Appl. Surf. Science 109-110, pp. 1519 (1997).

[2] S. Ameer-Beg, W. Perrie, S. Rathbone, J. Wright, W. Weaver, H. Champoux: Femtosecond laser microstructuring of materials, Appl. Surf. Science 127-129, pp. 875-880 (1998).

[3] J. Schille, R. Ebert, U. Loeschner, P. Scully, N. Goddard, H. Exner: High repetition rate femtosecond laser processing of metals, Proc. SPIE, Vol. 7589, 758915 (2010).

[4] T. Tamaki, W. Watanabe, J. Nishii, K. Itoh: Welding of transparent materials using femtosecond laser pulses, Jpn. J. Appl. Phys. 44, pp. L687-L689 (2005).

[5] Tsing-Hua Her, R.J. Finlay, C. Wu, S. Deliwala, E. Mazur: Microstructuring of silicon with femtosecond laser pulses, Appl. Phys. Letters 12, pp. 1673-1675 (1998).

[6] Y. Kawakami, E. Ozawa: Tungsten microcone growth by laser irradiation, Appl. Surf. Science 218, pp. 175187 (2003).

[7] R. Ebert, F. Ullmann, L. Hartwig, T. Suess, S. Kloetzer, A. Streek, J. Schille, P. Regenfuss, H. Exner: Laser microsintering of tungsten in vacuum, Proc. SPIE, Vol. 7589, 75891G (2010).

[8] J.R. Krenn, F.R. Aussenegg, Nanooptik mit metallischen Strukturen, Physik Journal, No. 3, 39-45 (2002)

[9] P. Leiderer, C. Bartels, J. König-Birk, M. Mosbacher, J. Boneberg: Imaging optical near-fields of nanostructures, Appl. Phys. Letters 85, pp. 5370-5372 (2004).

[10] J. Wang, C. Guo: Ultrafast dynamics of femtosecond laser-induced periodic surface pattern formation on metals, Appl. Phys. Letters 87, 251914 (2005).

[11] Q. Z. Zhao, S. Malzer, L. J. Wang: Formation of subwavelength periodic structures on tungsten induced by ultrashort laser pulses, Optics Letters 32, pp. 19321934 (2007).

[12]B. Tan, K. Venkatakrishnan: Synthesis of fibrous nanoparticle aggregates by femtosecond laser ablation in air, Optics Express 2, pp. 1064-1069 (2009).

[13] Quan-Zhong Zhao, S. Malzer, Li-Jun Wang: Selforganized tungsten nanospikes grown on subwavelength ripples induced by femtosecond laser pulses, Optics Express 24, pp. 15741-15746 (2007).

(Received: June 7, 2011, Accepted: December 21, 2011) 